\title{
Estágio Supervisionado Curricular em Matemática: o Sequenciamento e o Ritmo em uma Oficina Sobre Estatística
}

\section{Supervised Curricular Internship in Mathematics: Sequencing and Rhythm in a Statistics Workshop}

\author{
Patrícia Santana Costa ${ }^{a}$; Flávia Cristina de Macêdo ${ }^{a}$; Ana Virginia de Almeida Luna*a
}

${ }^{a}$ Universidade Estadual de Feira de Santana. BA, Brasil.

*E-mail: avaluna@uefs.br

\begin{abstract}
Resumo
Este artigo apresenta algumas reflexões sobre a formação de professores que ensinam matemática, tomando como objeto o ensino de estatística durante o estágio. Para isso, buscamos identificar e analisar a prática pedagógica no ambiente de desenvolvimento do Estágio Curricular Supervisionado de conteúdos de estatística quanto ao sequenciamento e ao ritmo no contexto de sala de aula. Para tanto, o procedimento metodológico utilizado foi à observação. Os dados foram coletados durante a realização de uma das oficinas, fruto das atividades desenvolvidas no componente Estágio Curricular Supervisionado em Matemática III, da grade curricular do curso de Licenciatura em Matemática da Universidade Estadual de Feira de Santana. A filmagem foi o instrumento de registro usado para esse fim. Apoiamo-nos também nos materiais produzidos pelo grupo para obtermos dados complementares, como o planejamento e as narrativas. Entre os resultados, podemos destacar que desenvolvimento de projetos em uma abordagem interdisciplinar pode favorecer a educação estatística na formação inicial de professores que ensinam matematica. Para tanto, o sequenciamento adotado pelas professoras pode, também, ajudar outros professores a analisarem a proposta imprimindo um novo ritmo na organização de uma sequência no ambiente escolar. Dessa forma, podemos inferir que a inserção de atividades em diferentes contextos escolares pode provocar mudanças no sequenciamento e no ritmo da prática pedagógica por motivos variados.
\end{abstract}

Palavras-chave: Formação de Professores. Estágio Curricular Supervisionado em Matemática. Sequenciamento. Ritmo.

\begin{abstract}
This article presents some reflections on the formation of teachers who teach mathematics, taking as object the teaching of statistics during the internship. For this, we seek to identify and analyze the pedagogical practice in the development environment of the Supervised Curricular Internship with statistical content regarding sequencing and pace in the classroom context. For that, the methodological procedure used was observation. The data were collected during the realization of one of the workshops, as a result of the activities developed in the Supervised Curricular Internship in Mathematics III, component, of the curriculum of the Mathematics Degree course at the State University of Feira de Santana. Filming was the recording instrument used for this purpose. We also rely on the materials produced by the group to obtain complementary data, such as planning and narratives. Among the results, we can highlight that project development in an interdisciplinary approach can favor statistical education in the initial training of teachers who teach mathematics. To this end, the sequencing adopted by the teachers can also help other teachers to analyze the proposal by printing a new pace in the organization of a sequence in the school environment. Thus, we can infer that the insertion of activities in different school contexts can cause changes in the sequencing and pace of
\end{abstract} pedagogical practice for different reasons.

Keywords: Teacher Training. Supervised Curricular Internship in Mathematics. Sequencing. Rhythm.

\section{Introdução}

As discussões referentes à formação de professores têm sido ponto de pauta em muitos eventos nacionais, a exemplo dos seminários promovidos pela Associação Nacional pela formação dos profissionais da Educação (ANFOPE) e Associação Nacional de Pós-Graduação e Pesquisa em Educação (ANPED), colocando em debate o teor das diretrizes propostas ao longo das últimas décadas (Dourado, 2016; Gatti et al., 2019). Na área da Educação Matemática, essas discussões têm se intensificado e colocado em pauta os possíveis itinerários formativos delineados para a formação de professores que ensinam matemática para atuar na Educação Básica.

Manrique (2009), ao analisar uma amostra de projetos pedagógicos dos cursos de Licenciatura em Matemática, faz algumas reflexões sobre a legitimidade das atividades propostas nesses cursos. A autora sinaliza que há a necessidade de investigações de experiências pedagógicas vivenciadas, para a articulação de conhecimentos específicos e pedagógicos. Para isso, consideramos pertinente que os próprios cursos promovam ações em parceria constante entre as instituições formadoras e os sistemas e redes de ensino e suas instituições. Essa premissa tem sido sinalizada na última década e legitimada nas diretrizes recentes (Brasil, 2015; 2019). Argumentamos que essa articulação deve estar presente ao longo do curso, mas é durante a realização do estágio, componente obrigatório, que há a possibilidade de desenvolvimento de um maior vínculo entre universidade e escola.

Segundo os documentos oficiais, o Estágio Curricular 
Supervisionado $^{1}$ é compreendido como um componente obrigatório da organização curricular das licenciaturas, sendo uma atividade específica intrinsecamente articulada com a prática e com as demais atividades de trabalho acadêmico (Brasil, 2002; 2015; 2019). Pesquisas têm sinalizado a realização de atividades de estágio em duas perspectivas: como campo de pesquisa e colaboração (Gonçalves Júnior, 2009; Medeiros, 2010; Cavalcante; Honorato, 2012; Pimenta \& Lima, 2019). Medeiros (2010) e Júnior (2009) apresentam a ideia de estágio como colaboração na perspectiva de que professores, supervisores e estudantes trabalharem em conjunto. Medeiros (2010, p. 8) salienta que “[...] o estágio supervisionado quando ocorre de maneira colaborativa pode proporcionar significados positivos aos sujeitos que se constituem professores". Entretanto, Pimenta e Lima (2019) apresentam a ideia de Estágio como campo de pesquisa, enfatizando a importância da mesma para a formação acadêmica e para a constituição da identidade profissional ${ }^{2}$. Nesta perspectiva, defendemos que o futuro professor(a) que ensina matemática pode se constituir um profissional críticoreflexivo e pesquisador.

Pensado no estágio como um componente propício para a realização de pesquisas, voltamos nossos olhares para as produções realizadas durante o curso. A literatura tem sinalizado que há diferentes formas de registros que podem ser realizados pelos estudantes, como por exemplo, relatórios, narrativas, relatos de experiências construídos em parcerias com os agentes envolvidos (Teixeira \& Cyrino, 2015; Pimenta \& Lima, 2019). Os autores argumentam que o relatório de estágio, por exemplo, pode vir a constituir um importante instrumento reflexivo sobre a prática. Entretanto, observa-se nesses artigos, que apesar de destacarem as potencialidades dos relatórios, da importância da reflexão do que esses relatórios podem gerar, estes trabalhos não evidenciam uma sistematização das ações desenvolvidas em sala, nem o compasso dessas ações.

A existência dessa lacuna nos motivou a desenvolver um estudo mais sistemático sobre o tema. Diante disso, na presente investigação, buscamos, intuitivamente, identificar e analisar como as estagiárias transformam o conteúdo de estatística para fins de ensino na Educação Básica, a partir de orientações do componente de Estágio quanto à organização e tempo no contexto da sala de aula. Em consonância com Lopes (2014), escolhemos a unidade temática Estatística e Probabilidade por ter se revelado um poderoso aliado para transformação e interpretação de informações brutas em dados que permitam ler e compreender uma realidade. E por ser uma temática pouco abordada na formação inicial.

$\mathrm{Na}$ próxima seção, iremos (re)apresentar o objetivo em termos teóricos. Para isso, mobilizaremos alguns conceitos da teoria dos códigos de Basil Bernstein considerados relevantes para compreender o fenômeno.

\section{A Prática Pedagógica em Diferentes Contextos e o Ensino de Estatística}

Inspirados em Bernstein (2003), podemos dizer que tanto no contexto escolar quanto no espaço acadêmico circulam diferentes textos. Esses textos, aqui, são entendidos como qualquer forma de comunicação expressa de diferentes maneiras: falada, escrita, visual, espacial ou expressa na postura ou na vestimenta (Bernstein, 2003).

Ao tomarmos o estágio como objeto de estudo, estamos considerando que ele se constitui em um tipo de prática pedagógica que possibilita produzir, mobilizar e/ ou transformar textos advindos do espaço acadêmico para a prática pedagógica do contexto escolar. Compreendemos a prática pedagógica como um contexto social por meio do qual é realizada tanto a produção como a reprodução da cultura, podendo ser vista em termos de relações entre diferentes sujeitos, como por exemplo, entre o professor e os estudantes no contexto escolar; entre professores e estagiários; entre supervisor e estagiários; entre supervisor e professor da educação básica (Bernstein, 2000, 2003).

Conforme, Pimenta e Lima (2006), o estágio se constitui como um campo propício para a produção de novos textos. Na mesma direção, Santana e Grilo (2013) apontam que a articulação entre o que os estudantes veem nas diversas disciplinas específicas e os elementos da prática pedagógica vivenciados por eles durante o Estágio podem ser fonte de produções textuais. Para estas autoras, as ações desenvolvidas devem ser mediadas por debates teóricos que contribuam na formação de cidadãos conscientes para atuar na Educação Básica.

Aroeira (2009) argumenta que as atividades envolvendo a articulação entre universidade e escola podem ser pautadas por relações de coparticipação, parceria e colaboração, num diálogo constante entre essas instituições para culminar na realização da regência. Teixeira e Cyrino (2015) argumentam que o Estágio de Regência se constitui uma oportunidade de desenvolvimento profissional para futuros professores(as) de Matemática. Nesta perspectiva, Silveira e Almeida (2009) sinalizam que as ações desenvolvidas durante o estágio de regência podem assumir diferentes designs, como podemos ver a seguir:

1-Regência de classe: pressupõe a iniciação profissional como um saber que busca orientar-se por teorias de ensinoaprendizagem para responder às demandas colocadas pela prática pedagógica à qual se dirige.

1 Para evitar repetições denominaremos de Estágio Curricular Supervisionado apenas estágio.

2 Inspirados em Bernstein (2000) estamos considerando que a formação da identidade profissional está relacionada com as relações de poder e controle instituídas e reguladas no contexto e que possibilita subsídios para entender as diferentes participações dos sujeitos. Entretanto, neste artigo não daremos foco ao conceito de identidade. 
2-Projetos de extensão: pressupõe a realização de atividades na forma de seminários, mini-cursos e oficinas para professores, alunos e demais comunidade escolar ou ainda grupos de educação não-formal sobre temas específicos de cada curso de licenciatura.

3-Projetos de pesquisa: pressupõe propostas de pesquisa educacional acerca de "inquietações" próprias do processo de ensino-aprendizagem e suas especificidades.

4-Monitorias: pressupõem acompanhamento ao trabalho de educadores em grupos de educação de jovens e adultos, grupos da terceira idade, etc. com roteiro e relatórios de atividades.

5-Seminários temáticos e outras possibilidades da realidade situacional da universidade e unidades escolares. (p.10-11).

Em nossa investigação, dentre as modalidades de ensino oferecidas pelo componente Estágio Curricular Supervisionado, optamos pela realização de oficinas por considerar uma modalidade legítima. Em consonância com Ferreira (2000), entendemos oficina como um momento de interação e envolvimento entre os sujeitos que oportuniza ao professor e aos estudantes refletir sobre métodos, instrumentos e estratégias que podem ser utilizadas para trabalhar com conteúdos em sala de aula.

Para analisarmos a implementação da oficina, assim como Luna (2012), tomamos como foco a teoria de Basil Bernstein e nos apoiamos nos princípios da classificação e do enquadramento para nos auxiliar na compreensão dos processos de comunicação na prática pedagógica. Para Bernstein (2000) a classificação possibilita analisar as relações entre as categorias, sejam elas sujeitos (professor e alunos) ou textos enunciados e produzidos pelos diferentes sujeitos, podemos tomar como exemplo os textos enunciados por professores da educação básica e os textos enunciados pelos professores da universidade, ou pelos estagiários e o supervisor, visto que são delimitadas fronteiras em relação ao que pode ser dito em cada uma delas. Essas fronteiras entre as categorias e entre o que será considerado como texto legítimo ${ }^{3}$ para a comunicação são delimitadas pelas relações de poder.

Segundo Bernstein (2000) o princípio de enquadramento refere-se ao controle e, que, por sua vez, regula a comunicação pedagógica. Podemos tomar como exemplo a relação entre professores e estudantes no contexto escolar em que foram desenvolvidas as atividades de estágio. Esse princípio possibilita a apresentação do conteúdo quanto à forma, ao sequenciamento e ao ritmo. Para o autor o conceito de sequenciamento diz respeito à ordem em que os conteúdos são desenvolvidos e organizados na relação pedagógica, e o ritmo, refere-se à velocidade prevista para uma determinada prática ser desenvolvida, a partir da relação pedagógica entre professor e estudantes.

Ainda de acordo com Bernstein (2000), podem ocorrer variações nos princípios de classificação e de enquadramento. No caso, da classificação, ela pode ser mais forte se houver entre professor e aluno relações de poder explícitas ou pode ser mais fraca se as relações de poder forem implícitas. Enquanto que, no princípio de enquadramento as variações entre fraco e forte se dá quando há um controle explícito pelo professor sobre a seleção, o sequenciamento e os ritmos da prática pedagógica, o enquadramento é mais forte. No caso do enquadramento mais fraco, há um controle aparente maior no processo de comunicação pelo aluno. Segundo Bernstein (2000), a variação do enquadramento mais forte pode estar associada aos alunos que são rotulados em termos de atenção, interesse, cuidado e esforço, enquanto que, no caso de um enquadramento mais fraco, essa denominação pode estar relacionada aos alunos que demonstram serem criativos, interativos e autônomos.

Podemos inferir que as atividades de estágio desenvolvidas no contexto da universidade e em diálogo com as escolas campo de estágio possibilitam diferentes tipos de organização no que se refere ao planejamento das ações. Visualizamos que, durante o estágio, os estudantes do curso de Licenciatura em Matemática podem organizar o sequenciamento dos conteúdos escolares de diferentes formas a depender das necessidades e da organização já definida pela instituição escolar ou podem utilizar outros critérios.

Por exemplo, podem seguir instituições escolares que apresentam uma estrutura linear, abordam os conteúdos de acordo como são apresentados em alguns livros didáticos adotados pela instituição ou pela sequência do planejamento do curso elaborado no início do ano letivo, como é comum na tradição da matemática escolar; nos estágios, outra modalidade pode ser a organização de sequências de ensino em torno de um tema interdisciplinar ou, ainda, a partir de questões do dia a dia ou de outras ciências, como foi proposto pelas estudantes de estágio, no caso dessa pesquisa. Segundo Luna (2012) o contexto em que os estudantes estão inseridos pode influenciar nas variadas formas de sequenciamento, possibilitando que professores e estudantes imprimam ritmos diferentes, ou seja, o compassamento pode ser mais lento ou mais acelerado.

A partir das considerações acima, podemos constatar que as variações no princípio de enquadramento regulam o sequenciamento e ritmo de práticas pedagógicas em diferentes contextos. No presente estudo, focamos lentes nos princípios que regulam o sequenciamento e o ritmo subjacentes nas práticas de sala de aula de duas estagiárias do curso de Licenciatura em Matemática durante a implementação de uma oficina sobre estatística.

A estatística no final da década de 1990 foi introduzida nos documentos oficiais da educação básica, denominada como Tratamento da Informação. No entanto, desde 2012 com a implementação Pacto Nacional pela Alfabetização na Idade Certa (PNAIC), tem sido abordada como Educação

3 Bernstein (2000) denomina texto legitimo quando esse texto é produzido com um significado pertinente ao contexto de uma determina prática pedagógica. 
Estatística, conforme pode ser visto no Caderno 7 (Brasil, 2014), neste documento é apresentada uma discussão pela educadora matemática Gitirana sobre a pesquisa como um dos eixos estruturadores da estatística na escola, desde os anos iniciais (Brasil, 2014). Esta pesquisadora aponta que realizar pesquisa possibilita não somente a formação estatística do cidadão, bem como, a formação científica.

Atualmente, no mais recente documento oficial, a Base Nacional Comum Curricular (Brasil, 2019), também é abordada a relevância da Educação Estatística para o desenvolvimento de habilidades investigativas. Além disso, pesquisadores no âmbito nacional e internacional corroboram com esta afirmativa (Guimarães, 2019; Cazorla et al., 2017; Sharma, 2017) preocupados com os processos de ensino e de aprendizagem da estatística desde o início da escolaridade dos estudantes e no decorrer de toda a educação básica.

Face ao exposto, o objetivo da pesquisa foi identificar e analisar a prática pedagógica no ambiente de desenvolvimento do Estágio Curricular Supervisionado de conteúdos de Estatística quanto ao sequenciamento e ao ritmo no contexto de sala de aula, para fins de ensino na Educação Básica. $\mathrm{Na}$ próxima seção, apresentaremos o contexto da pesquisa realizada durante o Estágio Curricular Supervisionado em Matemática III, em parceria com uma escola da rede pública de ensino.

\section{Contexto}

A orientação de que os estágios sejam oferecidos a partir do início da segunda metade do curso foi claramente proposta a partir de 2002, quando o Conselho Nacional de Educação (CNE) instituiu as Diretrizes Curriculares Nacionais para a Formação de Professores da Educação Básica em nível superior (Brasil, 2002). Segundo os documentos oficiais o Estágio Curricular Supervisionado ${ }^{4}$ é compreendido como um componente obrigatório da organização curricular das licenciaturas, sendo uma atividade específica intrinsecamente articulada com a prática e com as demais atividades de trabalho acadêmico (Brasil, 2015). Para essa investigação, tomamos como foco de análise as atividades desenvolvidas entre uma universidade pública no interior da Bahia e uma escola da rede estadual de ensino do mesmo município.

No contexto da universidade, podemos destacar que o componente de Estágio ofertado procurou atender as recomendações do Conselho Nacional de Educação (CNE por meio das resoluções $\mathrm{CNE} / \mathrm{CP} \mathrm{N}^{\circ}$. 01 e $\mathrm{N}^{\mathrm{o}}$. 02/20025. Estas Resoluções estabelecem um mínimo de 400 horas de Estágio Supervisionado distribuídas a partir do quinto semestre do curso. A matriz curricular do curso oferece quatro componentes de 105 horas denominadas Estágio Curricular Supervisionado de Matemática I, II, III e IV.

Neste artigo, apresentamos dados que foram produzidos em parceria com o componente Estágio Curricular Supervisionado em Matemática IV. Neste componente, os estudantes tiveram a oportunidade de estudar, investigar, elaborar, planejar, implementar e analisar as atividades tendo como foco a Educação Básica. Em função da riqueza dos dados, focaremos apenas no momento de implementação de uma atividade inovadora em que as estagiárias, após período de ambientação na escola campo, elegeram a ser trabalhada para atender as necessidades sinalizadas pelos estudantes do Ensino Médio.

Socializaremos, neste artigo, dados que foram coletados na oficina intitulada "Letramento estatístico: a HIV/Aids no Brasil" que foi ministrada por duas estudantes/estagiárias que estavam cursando o componente a quem denominamos de professoras. Nesta investigação, mobilizamos os conceitos bensteinianos de sequenciamento e o ritmo para analisar os dados produzidos durante a implementação da atividade proposta. Participaram da oficina quinze estudantes do $1^{\circ}$ ano do Ensino Médio e que foram identificados por pseudônimos.

$\mathrm{Na}$ próxima seção, apresentaremos o delineamento do método adotado em nossa investigação.

\section{Método}

Como buscamos identificar e analisar a prática pedagógica no ambiente de desenvolvimento do Estágio Curricular Supervisionado de conteúdos de estatística quanto ao sequenciamento e ao ritmo no contexto de sala de aula, optamos por uma abordagem qualitativa como posto por Creswell (2010) e Flick (2014). Considerando nosso objeto de estudo, esta investigação enquadra-se na modalidade de pesquisa empírica, em que a interpretação dos dados foi construída a partir do recorte de momentos.

Tomamos a observação como procedimento para obtenção de dados. Conforme Adler e Adler (1994), a observação é praticada no contexto natural, em meio aos atores que participam da interação e seguem o fluxo natural da sua vida cotidiana. A observação, de acordo com a concepção apresentada, oferece uma vantagem para o observador dessa complexidade do mundo, na qual conexões, correlações e causas podem ser testemunhadas na forma em que se mostram. Os observadores qualitativos não estão amarrados em categorias pré-determinadas para medir as suas respostas, mas são livres para pesquisar conceitos e categorias que apareçam e que deem significado aos seus sujeitos. Os registros das observações foram captados por meio de filmagens, consideradas centrais tendo como foco o sequenciamento e o ritmo em quatro momentos da oficina problematização, resolução da tarefa, socialização, sistematização e reflexão. De forma complementar, utilizamos os registros da resolução da tarefa dos estudantes e a narrativa produzida pelas estagiárias. 
A seleção e a análise dos dados foram realizadas com base em um levantamento preliminar, cujo foco recaiu no sequenciamento e o ritmo instaurado durante a implementação da oficina. A primeira fase da análise envolveu a avaliação das filmagens, a identificação e a transcrição de trechos que se relacionavam com o objetivo do artigo. Já na segunda, fizemos a leitura, linha por linha, dos referidos trechos e sua categorização e, em seguida, comparamos os dados e agrupamo-los em categorias mais gerais. Na terceira fase, os momentos selecionados foram examinados e discutidos à luz da literatura e de conceitos da teoria de Bernstein (2000).

Na seção que se segue, apresentaremos os dados avaliados e categorizados com os seus momentos. Durante a descrição das análises, utilizaremos pseudônimos para identificar os graduandos, os estudantes e finalizaremos com a discussão e as considerações finais.

\section{Resultados e Discussão}

Neste artigo, preocupamo-nos identificar e analisar a prática pedagógica no ambiente de desenvolvimento do Estágio Curricular Supervisionado de conteúdos de estatística quanto ao sequenciamento e ao ritmo no contexto de sala de aula. Os resultados apresentados estão relacionados à proposta delineada para a realização da oficina. A princípio o design adotado foi elaborado, planejado e refinado durante os encontros presenciais com a professora orientadora de estágio e tomou como referência as necessidades advindas do contexto escolar, identificadas durante o período de observação e ambientação. A proposta desenvolvida tinha por propósito interpretar informações de natureza científica e social obtidas da leitura de gráficos e tabelas, realizando previsão de tendência, extrapolação e interpretação, em consonância com o que propõe Arteaga et al. (2015). O tema gerador adotado para o desenvolvimento das atividades que foram realizadas foi Virus da Imunodeficiência Humana (HIV)/Sindrome da Imunodeficiência Adquirida (Sida/Aids).

$\mathrm{Na}$ sequência, apresentaremos os momentos que constituíram o processo de implementação da tarefa ${ }^{6}$ e que nos possibilitou delinear o sequenciamento e o ritmo da prática pedagógica instaurada na Educação Básica. Para a realização da tarefa, os estudantes foram desafiados a utilizar as informações expressas no gráfico e tabela para fazer inferências sobre a situação do HIV/Aids no Brasil; resolver a tarefa tomando como referência os dados apresentados no gráfico e na tabela sobre HIV/Aids; analisar as informações expressas no gráfico e na tabela como recurso para a construção de argumentos sobre contaminação e prevenção do HIV/Aids. A proposta foi planejada contemplando os seguintes momentos: problematização, resolução da tarefa, socialização, sistematização e reflexão.

\subsection{Problematização}

Para introduzir a implementação da proposta, a professora utilizou como atividade disparadora um vídeo que tinha por propósito conscientizar a população mais jovem sobre os riscos de contrair o Vírus da Imunodeficiência Humana (HIV). O vídeo era um documentário intitulado "HIV HOJE" apresentado pelo Dr. Dráuzio Varela ${ }^{7}$ com duração de catorze minutos e cinquenta e sete segundos, que sinalizava que paramos de educar os jovens sobre a doença, riscos e tratamento. Segundo depoimento, houve um crescimento de $11 \%$ do índice de pessoas contaminadas nos últimos anos e que a população mais atingida são os jovens entre quinze e vinte e quatro anos no Brasil. Além disso, o vídeo retrata que o grupo com o maior índice de infectados no Brasil são os homossexuais e chama a atenção para o método de tratamento de pessoas que já foram infectadas, a importância do diagnóstico precoce é a melhor maneira de se prevenir. Após apresentação do documentário, a professora passou a dialogar com o grupo com o intuito de estimular o debate sobre tal assunto, como podemos observar no trecho a seguir:

(1) Professora A: O que o vídeo nos mostra? O que significa Aids e HIV? O que tem acontecido nos últimos anos? Como nos proteger contra esse vírus ?

(2) Luan/Aluno: Tem crescido o número de infectados no Brasil, principalmente entre jovens.

(3) Pablo/Aluno: [...] pensava que HIV e Aids tinha o mesmo significado. Agora entendi que HIV é o vírus e pode-se conviver com ele. E Aids é o estágio mais avançado.

(4) Professora A: Isso! Síndrome da Imunodeficiência Adquirida (Sida/Aids) é causada pelo Vírus da Imunodeficiência Humana (HIV). Ele pode ser transmitido durante a relação sexual sem uso de preservativo e por produtos sanguíneos. Mas, um dos maiores problemas é o preconceito. O que vocês fariam se uma pessoa estivesse com o vírus? Vocês se afastariam com medo do contágio?

(5) Bruno/Aluno: [...] na verdade quem deveria ter medo da gente era a pessoa que tem Aids, pois a imunidade dele fica baixa, pois qualquer risco de contaminação pode ser ruim pra ele.

(6) Professora B: Isso! [...] como é transmitido o vírus? Quais os meios de prevenção?

(7) Alice/Aluna: relação sexual, quando toca em sangue.

(8) Vitor/Aluno: [...] uso de objetos cortantes.

(9) Alice/Aluna: devemos usar preservativos e evitar compartilhar objetos, como seringas.Professora B: Isso! E qual a relação dessa temática com a matemática? O que de matemática aparece no vídeo? Quais são as informações?

(10) Alice/Aluna: o doutor falou que houve um aumento no índice de contaminação!

(11) Vitor/Aluno: Houve um aumento de $11 \%$. E hoje, os homossexuais são grupo de risco.

(12) Pedro/Aluno: [...] o grupo que mais é contaminado!

6 Tarefa é compreendida como um segmento de atividades da sala de aula dedicado ao desenvolvimento de uma ideia matemática particular (Stein \&

Smith, 2009)

7 Recuperado de https://www.youtube.com/watch?v=8vlVyOwz0J4 
(13) Professora B: Isso! Nós temos informações que o vírus contamina jovens entre 15-24 anos, o constitui um intervalo de risco que merece cuidados e orientações. Nessa faixa, os jovens estão iniciando suas atividades sexuais. Vejam que há informações estatísticas que precisam ser consideradas.

Inspirados em Bernstein (2000; 2003), podemos dizer que os princípios de classificação e enquadramento que regulam esta prática, apresentaram variações em diferentes momentos da aula. Em (1), (4), (6), (10) e (14), o princípio de classificação foi fortalecido, na relação de poder entre os sujeitos (o que podia ser dito), e os enquadramentos foram mais fortes nas relações de controle como produziam os textos sobre o tema em discussão. O trecho (1) mostra que a professora após a apresentação do vídeo sobre HIV/Aids instaurou o debate e discussão referente à temática abordada, gerando reflexões e questionamentos sobre a doença, contágio e tratamento, bem como os efeitos sociais. Neste momento, como os estudantes puderam apresentar opiniões, o enquadramento foi enfraquecido dando oportunidade de participação mais aberta a eles. Esse primeiro momento da sequência foi dividido em duas etapas, a saber: catorze minutos e cinquenta e sete segundos com apresentação do vídeo e quinze minutos de debate introdutório. $\mathrm{Na}$ segunda etapa, o ritmo ocorreu de forma mais acelerada, sendo restringido o tipo de texto a ser produzido pelos alunos, com uma classificação mais forte e um enquadramento mais fraco.
Observa-se que a professora tentou conduzir as discussões de forma que os estudantes compreendessem que a matemática pode ser uma aliada para a análise de problemas sociais. Entretanto, a forma de condução das reflexões poderia deixar mais explícita as narrativas com ênfase em informações relacionadas à matemática, permeando as orientações expostas nos Parâmetros Curriculares Nacionais - PCNs (Brasil, 1998) e atualmente descritas na BNCC (Brasil, 2018) para a exploração de dados estatísticos.

\subsection{Resolução da tarefa}

Neste momento, as professoras deram continuidade com a implementação da tarefa. Ela tinha por propósito levar os alunos a explorar leitura, interpretação de gráficos, tabelas e refletir sobre o crescimento nos últimos anos da HIV/Aids no Brasil. Para elaboração da tarefa, as professoras tomaram como referência o Boletim Epidemiológico de HIV/AIDS. Inicialmente, a professora solicitou que os estudantes lessem trechos do boletim. A leitura foi realizada pelos alunos sem interrupções para comentários. Esse momento da sequência teve uma duração de dois minutos. Em seguida, iniciou-se o debate e interpretação dos dados apresentados para que os estudantes pudessem realizar a tarefa com uma roda de conversa que durou dez minutos. Após esse momento, as professoras apresentaram o gráfico a seguir para uma análise preliminar:

Figura 1 - Imagem com o gráfico apresentado na tarefa para análise Gráfico 3. Taxa de detecção de aids (por 100 mil habitantes) segundo regiâo de residência por ano de diagnóstico. Brasil, 2005 a $2014^{(1)}$.

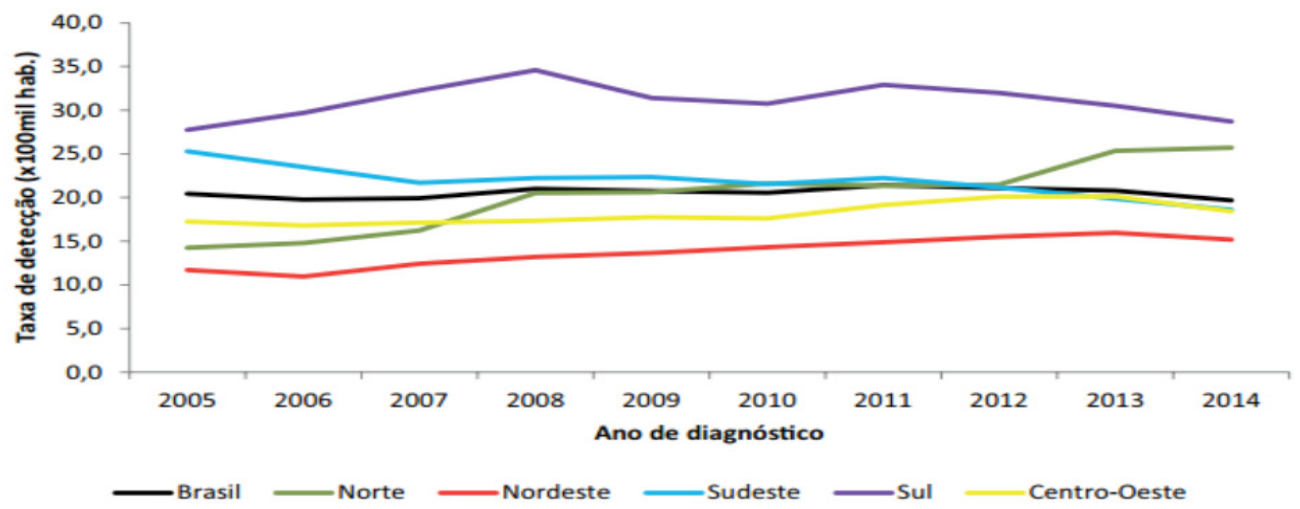

Fonte: MS/SVS/Departamento de DST, Nids e Hepatines Virois

Nowe: (1) Casos notificatos no Sinen e Siscel/Siclom até 30/06/2015 e no sim de 2000 ané 2014.

Fonte: Os autores.

$\mathrm{Na}$ sequência foram feitos alguns questionamentos como nos mostra o episódio abaixo:

(14) Professora B: De que trata o gráfico?

(15) Ruan/Aluno: taxa de detecção de aids

(16) Camila/Aluna: a taxa relacionada a Região de residência

(17) Professora A: O que significa os números que aparecem na linha horizontal? E na vertical?

(18) Luan/Aluno: Na horizontal são os anos em que a pesquisa foi realizada e mostra a variação que ocorreu de 2005 a 2014
(19) Alice/aluna: Na vertical a taxa de detecção por habitante, mas os valores são baixos

(20) Professora A: Não! Veja que a escala indicada na vertical está multiplicada por 100 mil habitantes. Neste caso, se faz necessário essa representação. Caso contrário o gráfico seria enorme. E agora, porque as linhas são coloridas? \{sequência crescente: vermelha/Nordeste, verde/Norte, amarela/Centro Oeste, preta/Brasil, azul/Sudeste e lilás/ Sul). Em que ano temos o pico da epidemia? Em que Região?

(21) Alice/Aluna: Parece que em 2008, na Região sul. 
(22) Professora B: O que acontece com o segmento da Região nordeste?

(23) Vitor/aluno: Há um crescimento de 2006 a 2013.

(24) Professora B: O que estamos fazendo? Estamos analisando e interpretando os dados expostos no gráfico de segmento. A que conclusão é possível chegar?

(25) Victor/aluno: Parece que a epidemia tem sido controla, exceto no norte que continua aumentando os casos de detecção.

O princípio de classificação que regula os excertos (15) e (18) foram mais fortalecidos e apresenta um texto diretivo. Observa-se que a professora consegue explorar alguns dados estatísticos, mantendo um ritmo compassado que durou dez minutos, mas os princípios de enquadramento também foram fortalecidos. $\mathrm{Na}$ linha (21), podemos perceber que a professora controle os textos a serem produzidos pelos estudantes. Em seguida, no sequenciamento evidencia que a forma de organização da atividade proposta pode contribuir para o desenvolvimento da oficina. Não podemos afirmar se o mesmo pode acontecer no período normal de aula em que se cumpri uma carga horária da disciplina. Para responder as questões a seguir, a turma solicitou mais quinze minutos.

Durante toda a tarefa as professoras realizaram intervenções nos grupos, porém foi perceptível que a maioria dos estudantes ainda apresentavam dúvidas. Por conta disso e do tempo disponível, elas resolveram iniciar a socialização das respostas dos grupos a fim de sanar coletivamente as dúvidas e dificuldades dos estudantes. Dessa maneira, os grupos que não conseguiram resolver determinadas questões poderiam observar a forma como os outros grupos resolveram a sua tarefa.

\subsection{A socialização da tarefa}

O episódio a seguir revela o momento da socialização da tarefa que durou quarenta minutos. Neste momento, os grupos foram convidados a socializarem as respectivas resoluções das questões. O trecho mostra a resolução das primeiras questões da tarefa, bem como as dificuldades de interpretação apresentadas pelos estudantes, como podemos observar a seguir:

(26) Professora A: Vamos analisar a primeira questão. Equipe A, como vocês analisaram?

(27) Ruan/Aluno: De acordo com o texto quantas pessoas vivem com HIV/ AIDS no Brasil?

(28) Camila/Aluna: foram registrados no Brasil 798.366 casos. [...] Foi fácil, porque só foi interpretar o texto.

(29) Professora A: E vocês [grupo B]?

(30) Luan/Aluno: somando de 1980 até junho de 2015 à $73,8 \%$ de contaminados pelo HIV/AIDS no Brasil, não teve nenhuma dificuldade não!

(31) Professora B: ele trabalhou a ideia de porcentagem e foi pegando dados do texto. E a segunda questão?

(32) Alice/Aluna: [grupo D] Em qual Região foi notificado, em percentual, o maior número de casos de AIDS no Brasil? Nordeste.

(33) Aluna/ Luna: [grupo C] a gente aqui colocou Rio Grande do Sul.
(34) Luan/Aluno: [grupo B] Região Sul.

(35) Professora: Região Sul! E vocês [grupo A]?

(36) Vitor/Aluno: a concentração mais acentuada está nas capitais do Sul e do Sudeste. Destacam municípios do Estado de São Paulo.

(37) Professora B: eu quero que vocês [...] leia a questão novamente e analisem essas respostas de vocês ai, cada equipe tem dois minutinhos. [...]

(38) Luan/Aluno: em qual Região?

(39) Alunos: Sul!

No excerto (27), o princípio que regula a classificação (o que deve ser dito) diz respeito ao texto que foi identificado como não reconhecido pelos estudantes. Os trechos que seguem com as falas dos estudantes revelam as dificuldades dos estudantes referentes à interpretação das questões da tarefa. Os estudantes só conseguiram produzir seus textos quando o princípio do enquadramento foi enfraquecido. Segundo Luna (2012), isso ocorre porque a professora controlara a sequência de formas diferentes, em algumas situações de forma mais rígida, em outras, mais flexível. Em virtude disso, a professora conduziu a situação de forma reflexiva e deu mais dois minutos para refletirem. Entretanto, neste momento, a professora poderia propor uma investigação matemática que explorasse questões envolvendo porcentagem para que os estudantes pudessem analisar e conjecturar.

Em seguida, a professora deu continuidade às discussões referentes à socialização da terceira questão letra (a) da tarefa, que diz, quanto à detecção de casos de HIV/Aids notificados, observa-se no Brasil, em 2014, uma taxa de 20,5/100.000 habitantes, e em qual Região foi observada a maior taxa de detecção de HIV/Aids, em 2014? Para resolver essa questão os estudantes se apoiaram no gráfico apresentado anteriormente

(40) Professora B: pronto, vamos continuar! A terceira questão?

(41) Luan/Aluno: há professora! A gente só teve que procurar mesmo, simples!

(42) Professora B: procurar onde?

(43) Luan/Aluno: no gráfico!

(44) Alice/Aluna: No gráfico dá pra ver que a linha verde [Região Norte] bem 2014 ela subiu e as outras não [grupo B].

(45) Vitor/Aluno: é Região Sul [grupo A]

(46) Professora A: Sul! [...] o pessoal aqui vai tá trabalhando, porque Sul e porque Norte? Eles vão começar ali [grupo B].

(47) Luan/Aluno: porque Norte? A equipe aqui achou que a linha verde que ele tem uma elevação, eu tentei interpretar assim, ô! Que é algo maior, que subiu e aqui tá pra baixo, ai tá diminuído e esse tá subindo, entendeu?

(48) Professora A: você tentou interpretar o ano de 2014?

(49) Luan/Aluno: é de 2014 mesmo! [grupo B].

(50) Camila/Aluna: [...] aqui a gente colocou assim, que independente que a Norte subiu, ela não chegou ao nível da Sul [grupo A].

(51) Professora A: [...] vocês?

(52) Daniela/Aluna: nenhuma outra passa a Região Sul [grupo C].

(53) Professora B: [...] em nenhum momento, nenhuma 
Região, aqui ô! Conseguiu chegar na Região Sul.

(54) Luan/Aluno: então, porque aqui tá no gráfico deveria que todas as tabelas deve tá no zero não.

(55) Professora B: toda tabela não, porque aqui ô! Em 2005 não tinha zero casos de AIDS.

(56) Luan/Aluno: há entendi!

(57) Professora B: tão entendendo! A pesquisa ela começou de 2005 até 2014, então em 2005 não teve zero casos de AIDS, já tinham casos de AIDS.

(58) Luan/Aluno: foi o que não interpretei, se eu tivesse interpretado isso acredito que teria acertado.

(59) Professora B: [...] vocês também se prenderam um pouco ao início do gráfico, ele pediu em um ponto especifico, em 2014, então eu vou olhar no ponto especifico, certo!

A professora poderia trabalhar com os estudantes neste momento da socialização da tarefa os elementos para a leitura de um gráfico, o que possibilitaria aos alunos realizar analogias. Os estudantes perceberem que ao analisar o gráfico proposto nenhuma outra Região ultrapassou a Região Sul e obtiveram êxito na resolução da mesma. Também, foi perceptivo que alguns grupos conseguiram interpretar efetivamente a questão relacionando-a com a imagem. Mas, a professora poderia propor que os estudantes explorassem as diferentes representações gráficas para o mesmo conjunto de dados.

Logo após, a professora dá prosseguimento à socialização da terceira questão, letra (b) da tarefa, discutindo a respeito da taxa de detecção de HIV/Aids na Região Nordeste, como ilustra o episódio descrito a seguir:

(60) Professora B: Pronto, a letra (b) da terceira questão?

(61) Daniela/Aluna: Identifique no gráfico a taxa mínima e a taxa máxima de detecção de AIDS, de residência e ano de diagnóstico, na Região nordeste.

(62) Daniela/Aluna: a taxa mínima em 2006 e taxa máxima em 2013.

(63) Professora B: trabalhou com a Região Nordeste?

(64) Daniela/Aluna: Sim!

(65) Professora: Ok! Vocês aqui? [Equipe D].

(66) Alice/Aluna: a taxa mínima foi em 2006 de 10,0 e a taxa máxima em 2013 de 13,0.

(67) Professora A: certo! E qual foi à dificuldade nessa questão?

(68) Alice/Aluna: nenhuma, só é analisar o gráfico.

(69) Professora A: [...] Elas colocaram um dado a mais que é interessante, que foi o fato delas olharem no gráfico que aproximadamente, que a gente não consegue o valor exato, né!

(70) Alunos: é!

(71) Professora B: que aproximadamente foi 10,6 a mínima foi?

(72) Alunos: foi!

(73) Professora B: a questão pede isso! a equipe [grupo B]?

(74) Luan/Aluno: taxa mínima foi em 2006 e a taxa máxima foi em 2013.

(75) Professora B: a taxa mínima foi em 2006 e a taxa máxima foi em 2013, continuo batendo a tecla da interpretação. Quando vocês trabalharam a questão de mínimo e máximo olhando para o gráfico, qual foi a menor taxa? O pessoal aqui chegou até aproximar aqui 10,6. E vocês também chegaram?

(76) Luan/Aluno: não!

(77) Professora A: não! Só a equipe delas que chegaram, a aproximar 10,6 que foi em 2006! [...] trabalhou com a taxa, e detectou ali a taxa de detecção, só que o pessoal aqui eles não trabalharam com a taxa de detecção, eles trabalharam com o ano, só que em 2005 [...] a taxa de detecção foi menor do que 2006 ?

(78) Alunos: não, foi maior!

(79) Professora A: se você olhar aqui no gráfico, passa uma régua, quando eu passo aqui ô, olha aqui! tá conseguindo perceber, que em 2005 é a linha é maior, que no ano de 2006 é menor.

Esse trecho mostra o momento referente à discussão sobre a taxa mínima e máxima de detecção de HIV/Aids na Região Nordeste. $\mathrm{Na}$ sequência proposta, a professora poderia explorar conceitos básicos da estatística descritiva. Essas situações como as descritas, oportunizaram aos estudantes possibilidades de saber decodificar informações e atribuir significados, como posto por Lopes (2014). Em outras palavras, esse momento seria a oportunidade de fazer interpretações com base em conjuntos de dados, representações de dados ou mesmo com um resumo dos dados envolvendo taxa mínima e máxima de detecção de HIV/Aids. A partir, dessa explicação os alunos poderiam compreender efetivamente o que se pedia na questão, visto que, apenas uma equipe conseguiu compreender o que de fato seria essas taxas.

$\mathrm{Na}$ quarta e última questão que se pede para que os grupos construíssem uma tabela com a taxa de detecção de HIV/Aids por Unidade da Federação, 2014, para a Região nordeste. Logo após, a questão pedia para que os mesmos elaborassem uma tabela com a taxa de detecção de HIV/Aids por Unidade da Federação, 2014, para os estados que apresentam essa maior taxa, como ilustra as imagens a seguir:

Figura 2 - Imagem do gráfico para a resolução da última questão proposta na tarefa

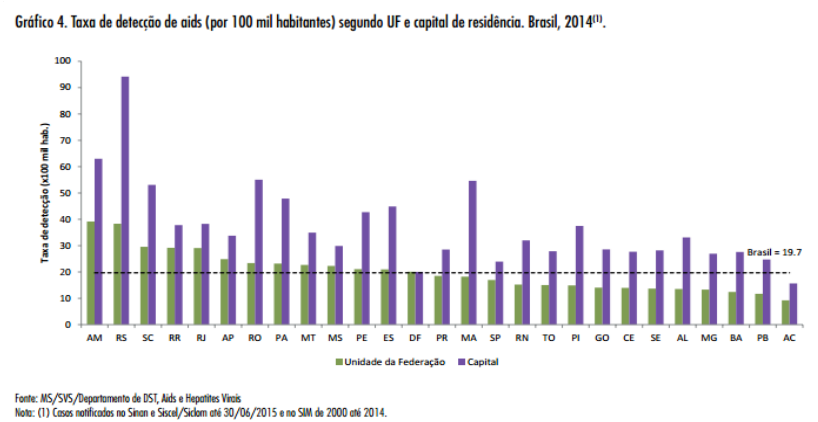

Fonte: Os autores.

Os alunos conseguiram construir as tabelas pedidas nas questões, mas no momento de localizá-las, o tempo estava curto para o término da oficina, pois teria ainda o momento da sistematização que será descrito a seguir.

\subsection{Momento da sistematização da tarefa}

Para a sistematização a professora fez uso do recurso Data show, enfatizando que tabelas e gráficos são recursos 
bastante utilizados para representar resultados de pesquisas e informações de forma organizada. Neste momento, a professora apresentou alguns modelos de gráficos, conduzindo a oficina com alguns questionamentos; para que servem gráficos e tabelas? Qual a diferença entre gráficos e tabelas? Quais os tipos de gráficos que vocês conhecem? como podemos observar a seguir:

(80) Professora: eu quero que vocês percebam, o objetivo mesmo da oficina, foi trabalhar com gráficos, com tabelas, mais também com a questão da interpretação, [...]. E pra vocês gráficos e tabelas serve pra que?

(81) Luan/Aluno: pra informar

(82) Vitor/Aluno: [...] pra representar [...] organizar!

(83) Bruna/Aluna: [...] pra ter uma ideia do que estar acontecendo.

(84) Daniele/Aluno: [...] pra fazer comparação também.

(85) Professora: Por exemplo: se você chegar na sala dos professores na porta e ter lá em 2007, eram 734 estudantes matriculados; em 2008, 753; em 2009, 777; e assim essa informação [...] isso ai fica legal? [a professora expõem os dados embaralhados].

(86) Alunos: não!

(87) Professora: mais se eu colocar assim [a professora representou os dados graficamente].

(88) Vivian/Aluna: o gráfico fica melhor.

(89) Luan/Aluno: mais organizado!

(90) Professora: [...] o que você consegue perceber?

(91) Alunos: uma elevação!

(92) Alunos: um aumento!

(93) Professora: maravilha! Justamente isso que é o gráfico.

(94) Luan/Aluno: Em professora? Como estava antes em número a pessoa pode até interpretar o número, mas a gente nunca vai imaginar se aumento ou diminuiu, olhando o gráfico a gente vai ver.

(95) Professora: Isso! [...] A gente chama esse gráfico de gráfico de linhas, o que vocês trabalharam, [...] a questão da comparação, ele bota um estado, uma Região, certo! Aqui um gráfico mais adequado para cada situação. [...] agora uma coisa que eu quero que vocês observem, eu não vi ninguém comentando, o gráfico de barra a gente analisa a largura dele?

(96) Vivian/Aluna: não! A altura.

(97) Professora: [...] vocês reparam que a largura são todas?

(98) Vitor/Aluno: A mesma! [...] Só a altura que muda.

(99) Professora: [...] Exatamente! E esse gráfico você chamou de que?

(100) Vitor/Aluno: circular

(101) Vivian/Aluna: redondo

(102) Alice/Aluna: pizza

(103) Professora: [...] Vocês não lembram não, no ensino fundamental $\mathrm{I},[\ldots]$ come um terço de pizza, esse gráfico é velho! [...] A gente chama esse gráfico de pizza, mas na verdade o nome dele é?

(104) Vivian/Aluna: setores

(105) Professora: setores! [...] e esse aqui foi o gráfico que a gente trabalhou, esse é o gráfico de que?

(106) Vitor/Aluno: de ondas

(107) Professora: de ondas?

(108) Vitor/Aluno: de evolução
(109) Professora: eu falei que foi o gráfico de linhas, né!

(110) Vitor/Aluno: de linhas

(111) Professora: a gente trabalhou com o gráfico de linhas, conseguimos perceber a elevação, a queda, não é isso!

(112) Vitor/Aluno: vai variando

(113) Professora: pronto!

Esse trecho mostra uma contradição quanto ao conceito mobilizado pela professora. A justificativa que foi exposta pelos estudantes não caracteriza um gráfico, como podemos observar nas linhas (87) à (95). Entretanto, a professora em vez de validar o argumento do estudante, poderia embasar a discussão descrevendo os principais elementos que caracterizam o gráfico, quanto ao título, número, fonte, legenda, o eixo horizontal e vertical. Em seguida, expor no slide os tipos de gráficos que são apresentados em jornais, revistas, livros didáticos entre outras fontes, mostrando diferentes possibilidades de se desenvolver investigações matemática. Além disso, a professora poderia trabalhar com a questão dos elementos de uma tabela, sinalizado em sua fala no episódio (80) a (84), mas não ampliou a discussão no decorrer da sistematização da tarefa.

Inspiradas em Bernstein (2003), podemos dizer que as professoras implementaram a oficina, de acordo com o sequenciamento proposto em seu plano de aula, mas imprimiram um ritmo de forma mais compassada, ou seja, com momentos de atividades mais lentas e em outros momentos acelerados, desenvolvendo a proposta em uma manhã, com a duração de dois horas e trinta minutos. No quadro a seguir, podemos observar a síntese do sequenciamento da prática e o tempo de cada momento da sequência, o que favoreceu a análise quanto ao ritmo da prática pedagógica no contexto escolar, como mostra o quadro abaixo:

Quadro 1 - sequenciamento e ritmo da oficina

\begin{tabular}{|c|c|c|}
\hline $\begin{array}{l}\text { Sequenciamento } \\
\text { Proposto na } \\
\text { Implementação } \\
\text { da Oficina }\end{array}$ & & Sequenciamento da Aula \\
\hline$\frac{\text { A }}{\text { Problematização }}$ & $\begin{array}{l}15 \mathrm{~min} \\
17 \mathrm{mim}\end{array}$ & $\begin{array}{l}\text { - vídeo sobre o aumento } \\
\text { significativo do HIV no Brasil. } \\
\text { - Discussão sobre o vídeo } \\
\text { proposto. }\end{array}$ \\
\hline $\begin{array}{l}\text { Resolução da } \\
\text { Tarefa }\end{array}$ & $\begin{array}{l}4 \mathrm{mim} \\
10 \mathrm{~min} \\
36 \mathrm{mim}\end{array}$ & $\begin{array}{l}\text { - Leitura de um texto motivador. } \\
\text {-Roda de conversa } \\
\text { - Entrega da tarefa e resolução dos } \\
\text { grupos. }\end{array}$ \\
\hline $\begin{array}{l}\text { Socialização da } \\
\text { Tarefa }\end{array}$ & $40 \mathrm{mim}$ & $\begin{array}{l}\text { - Socialização dos resultados } \\
\text { pelas equipes. }\end{array}$ \\
\hline $\begin{array}{l}\text { Sistematização } \\
\text { e Reflexão da } \\
\text { Tarefa }\end{array}$ & $15 \mathrm{mim}$ & $\begin{array}{c}\text { - Sistematização do conteúdo pela } \\
\text { professora. }\end{array}$ \\
\hline
\end{tabular}

Fonte: Os autores.

Tomando como referência o trabalho de Luna (2012), o sequenciamento empreendido na prática pedagógica contemplou quatro momentos: a problematização, a resolução da tarefa, a socialização e a sistematização. Observamos que 
o momento inicial ocorreu com o ritmo compassado, em trinta e dois minutos (15 para socialização do vídeo e dezessete minutos para as discussões).

Em seguida, as professoras deram início ao acompanhamento da resolução da tarefa por cada grupo. Nesse momento, foram utilizados cinquenta minutos, sendo quatro minutos para a leitura do texto motivador; dez minutos para a roda de conversa e trinta e seis minutos para entrega e resolução da tarefa pelos alunos. A atividade teve o ritmo lento, o que nos forneceu indícios de que tarefas similares não eram realizadas na prática pedagógica. Como os alunos apresentaram dificuldades na resolução-problema em estudo, as professoras no decorrer da tarefa circulavam por todos os grupos ajudando os mesmos. Na sequência, no momento da socialização dos resultados pelos alunos, foram utilizados quarenta minutos, visto que o ritmo estabelecido nesse momento foi bem lento, ocasionando assim na falta de tempo para os alunos socializarem a quarta questão da tarefa, pois faltavam poucos minutos para a oficina encerrar.

Conforme Nyambe \& Wilmot (2008), fatores contextuais podem impedir mudanças em uma determinada prática pedagógica. Ainda que o texto legítimo em relação ao sequenciamento dessa mudança seja reconhecido pela professora e pelos alunos, é possível que eles não consigam realizá-lo, por terem dificuldades em lidar com fatores contextuais. No caso da referida oficina, a diretora solicitou que as estagiárias liberassem os estudantes mais cedo por causa da falta de água. O sequenciamento planejado foi revisto e as estagiárias reorganizaram a rotina. Elas anteciparam o momento da sistematização.

Em seguida, houve o momento da sistematização do conteúdo proposto, as professoras prepararam uma aula expositiva com o uso de slides, sobre alguns modelos de gráficos, o qual durou quinze minutos. Apesar de a sistematização ter ocorrido em uma velocidade bem acelerada, as professoras conseguiram sistematizar ideias referentes à coleta, organização e interpretação de dados experimentais e extrapolação dos resultados da amostra para população, bem como seus conceitos utilizando os indicadores epidemiológicos.

\section{Conclusão}

Com este artigo, buscamos identificar e analisar a prática pedagógica no ambiente de desenvolvimento do Estágio Curricular Supervisionado de conteúdos de estatística quanto ao sequenciamento e ao ritmo no contexto de sala de aula. Os resultados encontrados permitiram observar que a prática pedagógica foi regulada pelos princípios de classificação e enquadramento, com diferentes variações entre mais fortes e mais fracas. De acordo com essas variações, as professoras controlaram as sequências propostas no seu plano de aula, em algumas situações o ritmo foi lento, porque os estudantes inferiram que o trabalho proposto era algo novo e era diferente do trabalho proposto na escola, não dando tempo para a finalização de algumas atividades propostas. A oficina implementada pelas professoras ocorreu de forma flexível, assim o ritmo apresentou variação de um maior a um menor compasso.

Para tanto, o sequenciamento adotado pelas professoras pode, também, ajudar professores a analisarem a proposta imprimindo um novo ritmo na organização de uma sequência no ambiente escolar. Dessa forma, podemos inferir que a inserção de atividades de estágio em diferentes contextos escolares pode provocar mudanças no sequenciamento e no ritmo da prática pedagógica por motivos variados. No que se refere à tarefa de estatística, identificamos possíveis causas das variações que ocorreram, a saber: propiciar o reconhecimento pelos alunos que questões relacionadas a temas do dia a dia ou de outras ciências podem ser resolvidas mediante o uso de ferramentas estatísticas; favorecer a aproximação de novos textos com dados estatísticos, os quais podem não fazer parte do programa do ano em curso.

Como implicação, podemos inferir que as ações desenvolvidas pelas professoras nos mostram que o modelo de sequenciamento adotado não contemplava a apresentação de conceitos, exemplos e exercícios, mas evidenciava outra possibilidade de sequenciamento para o trabalho com conteúdos estatísticos. Observamos que a inserção de artigos vinculados a outras áreas do conhecimento como tema disparador pode promover reflexões e, ao mesmo tempo, pode mobilizar diferentes saberes e provocar mudanças no próprio componente Estágio Curricular Supervisionado em Matemática. Roncaglio \& Battisli (2014) argumentam que o Estágio possibilita a produção/mobilização de saberes docentes necessários à prática a partir de reflexões desenvolvidas antes, durante e após o transcorrer das ações de ensino em sala de aula, como ocorreu com a produção da narrativa pelas professoras.

Desse modo, este artigo apresenta contribuições para o debate sobre a formação inicial de professores e coloca em evidência a necessidade de promover, nesses cursos, experiências formativas que priorizem diferentes componentes da Matriz Curricular. Sinalizamos a necessidade de desenvolvimento de novas pesquisas que contemplem essa temática. Avançar nos estudos empíricos será útil para identificarmos experimentos e refletirmos sobre suas possibilidades de desenvolvimento de estudo, planejamento e implementação de propostas em espaços formais de educação (níveis fundamental e/ou médio), em espaços alternativos e/ ou em outras modalidades educacionais.

\section{Referências}

Adler, P. A., \& Adler, P. (1994). Observational techniques. In: N. K. Denzin,. \& Y. S. Lincoln, Handbook of qualitative research. Thousand Oaks: Sage.

Arteaga, Pedro, Batanero, Carmen; Gea; María M., \& Contreras, J. Miguel. (2015). Conocimiento de la estadística y los estudiantes em futuros profesores: un estudio exploratório. Jornal Internacional de Estudos em Educação Matemática, 


\section{$8(3), 98-125$.}

Aroeira, K. P. (2009). O Estágio como Prática Dialética e Colaborativa: A produção de saberes por futuros professores. Tese (Doutorado- Programa de Pós-Graduação em Educação), Universidade de São Paulo. São Paulo.

Bernstein, B. (2003). Class, codes and control: the structuring of pedagogic discourse. Londres: Routledge; Taylor \& Francis Group.

Bernstein, B. (2000). Pedagogy, symbolic control and identity: theoryresearch Critique. Revised Edition. London: Taylor and Francis.

Brasil. (1998). Secretaria de Educação Fundamental. Parâmetros curriculares nacionais: Matemática / Secretaria de Educação Fundamental. Brasília: MEC

Brasil. (2002). Conselho Nacional de Educação/Conselho Pleno. Resolução CNE/CP 01/2002, de 18 de fevereiro de 2002. Institui Diretrizes Curriculares Nacionais para a Formação de Professores da Educação Básica, em nível superior, curso de licenciatura, de graduação plena. Brasília: MEC.

Brasil. (2014). Ministério da Educação. Secretaria de Educação Básica. Diretoria de Apoio à Gestão Educacional. Pacto Nacional pela Alfabetização na Idade Certa. PNAIC. Caderno7.

Brasil. (2015). Resolução CNE/CP n. 02/2015, de $1^{\circ}$ de julho de 2015. Define as Diretrizes Curriculares Nacionais para a formação inicial em nível superior (cursos de licenciatura, cursos de formação pedagógica para graduados e cursos de segunda licenciatura) e para a formação continuada.

Brasil. (2019). Resolução CNE/CP n. 02/2019, de 20 de dezembro de 2019. Define as Diretrizes Curriculares Nacionais para a formação inicial em nível superior (cursos de licenciatura, cursos de formação pedagógica para graduados e cursos de segunda licenciatura) e para a formação continuada.

Brasil. (2018). Base Nacional Comum Curricular (BNCC). Educação é a Base. Brasília, MEC/CONSED/UNDIME.

Cazorla, Irene; Magina, Sandra; Gitirana, Verônica; Guimarães \& Gilda Lisboa (2017). Estatística para os anos iniciais do ensino fundamental. Brasília: Sociedade Brasileira de Educação Matemática.

Cavalcante, J.L. \& Honorato, F.C. (2012). Estágio Supervisionado em foco: o olhar dos futuros professores de matemática. ecuperado de http://www.editorarealize.com.br/revistas/ epbem/trabalhos/Comunicacao 144.pdf

Creswell, J. W. (2010). Projeto de pesquisa: métodos qualitativo, quantitativo e misto. Porto Alegre: Artmed.

Dourado, Luis Fernandes. (2016). Formação de profissionais do magistério da educação básica: novas diretrizes e perspectiva. Comunicação \& Educação, 21(1), 28-39.

Ferreira, Carlos Augusto Lima. (2000). Oficina de ensino, formação e estágio no fazer do estudante de história. História Revista, 14(1), 37-50.

Guimarães, Gilda Lisboa. (2019). Educação Matemática com as Escolas da Educação Básica: interfaces entre pesquisas e salas de aula. Anais do Encontro Nacional de Educação Matemática, Cuiabá, MT, Brasil, 13.

Flick, U. (2014). An introduction to Qualitative Research. London: Sage Publications.
Gatti, B.A. Barretto, E.S.S., André. M;E.S.A. \& Almeida. P.C.A.. (2019). Professores do Brasil: novos cenários de formação. Brasília: UNESCO.

Gonçalves Júnior, M.A. (2009). Uma pesquisa sobre o estágio na licenciatura em matemática: considerações sobre as possibilidades metodológicas. Anais do Seminário Internacional de Pesquisa em Educação Matemática, Brasília, DF, Brasil, 4.

Lopes, Celi Espasandin. (2014). As Narrativas de Duas Professoras em seus Processos de Desenvolvimento Profissional, 28(49), 841-856.

Luna, A.V.A. (2012). A modelagem matemática na formação continuada e a recontextualização pedagógica desse ambiente em salas de aula. $184 \mathrm{f}$. Tese (Doutorado em Ensino, Filosofia e História das Ciências), Universidade Estadual de Feira de Santana, Salvador.

Manrique, A. L. (2009). Licenciatura em matemática: formação para a docência x formação específica. Educ. Matem. Pesq., $11(3), 515-534$.

Medeiros, C.M. (2010). Estágio Supervisionado: uma influência na constituição dos saberes e do professor de matemática na formação inicial. - Belém, 2010. Dissertação (Mestrado em Educação em Ciências e Matemática) - Universidade Federal do Pará, Belém.

Nyambe, J.; Wilmot, D. Bernstein. (2008). Theory of pedagogic discourse: a framework for understanding how teacher educators in a Namibian college of education interpret and practice learner-centred pedagogy. Anais do Bernstein Symposium, Cardiff: University of Cardiff, Wales, p. 348373.

Pimenta, Selma Garrido \& Lima, Maria Socorro Lucena. (2019). Estágios supervisionados e o Programa Institucional de Bolsa de Iniciação à Docência: duas faces da mesma moeda? Revista Brasileira de Educação. 24 (e240001).

Roncaglio, Viviane \& Battisti, Isabel Koltermann. (2014). A Produção de Saberes por um Grupo de Licenciandos em Matemática: Entendimentos Elaborados a Partir de um Estágio Supervisionado de Ensino. Editora Unijuí, 2(92), 165-189. Recuperado de https://www.revistas.unijui.edu.br/ index.php/contextoeducacao/article/viewFile/1892/3626

Santana, F. C. de M.; GRILO, J. de S. P. (2013) Programa novos talentos: possibilidades para o estágio supervisionado no curso de licenciatura em matemática. Anais do Encontro Nacional de Educação Matemática, Curitiba, PR, Brasil, 11.

Silveira, Jussara Maria Viana \& Almeida, Maria Claudice Rocha. (2009). Diretrizes para os Estágios Supervisionados nos Cursos de Licenciaturas da Faculdade José Augusto Vieira. Faculdade José Augusto Vieira - Lagarto, Sergipe.

Stein, M. H \& Smith, M. S. (2009). Mathematics Teaching in the Middle School, 3(4), 268-275.

Sharma, Sashi. (2017). Definitions and models of statistical literacy:a literature review, Open Review of Educational Research, 4(1), 118-133.

Teixeira, B.R. \& Cyrino, M.C.C.T. (2015). O Estágio de regência como contexto para o desenvolvimento da identidade profissional docente de futuros professores de Matemática. Alexandria Revista de Educação em Ciência e Tecnologia, v.8, n.3, p.131-149, 